\title{
Response latency in social psychological research
}

\author{
Brian Nosek \\ Yale University \\ Completed in fulfillment of the Theme Essay requirement \\ 10 February 1999
}

Running Head: Response latency

\section{Acknowledgments}

This paper was written under the direction of my advisor, Mahzarin Banaji. I am very appreciative of her motivational speeches and consistent support as I work to develop my writing skills. Also, much appreciation is due to Bethany Teachman who went over every word of this text with me, helping me to make my writing clearer and cleaner.

\begin{abstract}
With the rise of social cognition, use of response latency as a dependent variable has become common in social psychological research. Response latency has been used by researchers to investigate processes that are not easily testable with other methodologies, such as self-report. Response latency's usefulness as a methodological tool is notable due to its broad application in social psychology, from research on close relationships and attribution to investigations of the self and attitudes. This paper reviews the breadth of social psychological research that has used response latency to inform about mental representations, cognitive processes, and motivational tendencies.
\end{abstract}




\section{Response latency in social psychological research}

The only property of mental events that can be studied directly, in the intact organism, while the events are taking place, is their duration. ${ }^{1}$

Pachella, 1974, p. 43

Mental processes are grounded in real time (Posner, 1978). As such, thinking, judging, and behaving all must unfold over a period of measurable time. Researchers of information processing assume that the measurement of time can be exploited to infer the content of the cognitive processing that produces thought and behavior. Response latency is the time measurement between the introduction of a stimulus and the response to that stimulus. Response latency measurement has been central to cognitive psychology since the discipline's dramatic rise in the face of behaviorism. While behaviorists declared that no inferences about underlying mental events were possible, cognitive scientists skillfully dismantled that strong view with a collection of new research techniques that included response latency. Social psychologists co-opting of response latency for their own uses in the late 1970's spurred advances in social cognition. Research topics that had seemed untenable, such as examination of the underlying processes of social behavior, now had a powerful measure to tap mental processing. This paper reviews the areas of social psychology that have benefited from the use of response latency as a dependent variable.

While social psychologists did not use response latency heavily until the emergence of the social cognition approach, a sample of pre-social cognition research efforts did include response latency as a dependent variable. For example, some of the earliest known social psychological research attempted to distinguish liars from truth- 
tellers using response latency (Marston, 1920, 1925; English, 1926). The basic premise of this research was that more effort, and thus more time, would be required to make deceptive responses as opposed to truthful ones. Mixed results, and untenable claims (e.g., that the participants who were able to lie fast were just 'good liars') perhaps undermined the serious use of response latency as a measurement of deception. Early attitudes research using response latency presumed that the speed of response to an attitude object was an indicator of the extremity of that attitude ${ }^{2}$ (Burtt, 1941). However, Burtt found little empirical support for his hypotheses and declared response latency methodology a 'useless' technique for attitude measurement. In a study more optimistic about the utility of response latency, Osgood (1941) demonstrated that attitude polarization could be detected in their 'ease of judgment." ${ }^{3}$ Attitudes that were more extremely polarized in American culture were endorsed or rejected more quickly than attitudes having greater variability of endorsement. Interestingly in Osgood's research, cultural polarization of the attitude object, not the extremity of respondent's own attitude, predicted accelerated responding.

Even in early response latency research, topics of interest were not limited to intra-individual processes. An early group-interaction study used response latency to examine the effects of group agreement or disagreement on participation (Cervin, 1955). Cervin explained that in high agreement situations, persons 'excitatory potential' is high. As such, he demonstrated that individuals speak more quickly and more often in high agreement interactions.

\footnotetext{
${ }^{1}$ Today, this statement might need qualification with the advent of magnetic resonance imaging techniques. However, the usefulness of MRI techniques has not yet been realized.

${ }^{2}$ Burtt methods would more likely be considered to measure 'schematicity' in today's vernacular.

${ }^{3}$ Ease of judgment in modern terms might be termed accessibility or cognitive efficiency.
} 
Though social research using response latency was sporadic and flawed in its early years, it was not entirely a unique product of the cognitive revolution. Over time, response latency has developed into an essential dependent variable for the study mental processes relevant to social behavior. Current usage of response latency includes examination of mental representations, underlying cognitive processes, and motivational tendencies. Often, researchers use response latency as an 'unobtrusive' measure so that participants will not be alerted to the variables of interest in the study. In this way, researchers presume that they will obtain a more natural response. Response latency methodology has also been used to investigate the formation, maintenance, and use of mental representations. Response latency does not require conscious access to one's mental representations, and thus, is particularly useful in this area because introspection does not allow a substantive description of our own memory.

This paper provides an overview of the variety of ways response latency research has been used in social psychology. Although intended to be wide-ranging in its scope, the paper cannot review all of the social psychological research that has employed response latency as a dependent variable to illuminate social cognition, emotion, and motivation. The paper presents a review of representative papers in each of eight primary areas of social psychological research. These areas are split into two primary categories: interpersonal and intrapersonal processes. Four subsections within those broad categories target specific areas that have used response latency to understand relevant phenomena. 


\section{Attribution}

\section{Interpersonal processes}

Attribution researchers investigate how individuals explain their own behavior and the behavior of others. Heider (1958) and Kelley (1967) put forward theories regarding the process by which humans deconstruct personal events into dispositional, stimulus, and situational components to infer the cause of the event. Response latency measures have been particularly helpful in identifying the processes that underlie the dimensions along which individuals make causal analyses. In an influential book, Kelley (1967) proposed three dimensions that have been especially useful in delineating the nature of attributional judgments: Distinctiveness, which is characterized by an interaction that takes place between a particular person and stimulus, but does not take place in the context of other stimuli; consistency, which is defined by the reliability or regularity of the behavior for a particular individual; and consensus, which refers to the extent that others exhibit the same behavior toward a given stimulus. Kelley claimed that the perceiver reasons along these dimensions to infer the causal status of a particular event or class of events.

Information processing in attribution judgments. Applications of response latency methodology to social psychological research allowed researchers to assess attributional processes more directly than had been possible with previous methodologies. Smith and Miller (1979) were early proponents of the use of respone latency in social psychology. They argued that response latency techniques borrowed from cognitive psychology would be useful for building models of causal attribution and other types of social perception and cognition. As support for the use of response latency in attribution research, Smith and Miller showed that information that fits expected 
models of causality can be processed more quickly than information that is inconsistent with typical, previously encountered models of causality. In their experiments, response latency measurement revealed that the causal attribution process could be facilitated by mental representation of typical, expected causal scenarios. Smith and Miller's (1979) use of response latency provided unique insight into information processing during attributional judgments, and introduced response latency a field eager for new methodologies.

To advance understanding of information processing mechanisms in the attribution process, Ferguson and Wells (1980) used response latency measures to provide evidence that Kelley's three dimensions are in fact central to the process of making attributional judgments. Participants read a scenario in which causal responsibility was ambiguous. Immediately preceding an attributional judgment, participants were primed either with Kelley's informational criteria (distinctiveness, consistency, or consensus), or with alternative attributional criteria. They found that the speed of attributional judgments was facilitated when Kelley's informational criteria were presented compared with other information. Ferguson and Wells reasoned that priming informational criteria facilitates judgment time because descriptive information, such as Kelley's informational criteria, is part of actual cognitive processing in attributional judgments. As with Smith and Miller's experiments, using response latency techniques enabled Ferguson and Wells to drew inferences about the mechanisms by which attributional judgments are rendered.

Consistent with the goal of determining attributional mechanisms, response latency has also been used to measure the degree of facilitation a prime has for 
processing schema-consistent targets. Specifically, Zuckerman and Evans (1984)

postulated that attributional judgments are schema-driven, such that particular pieces of information activate distinct attributional patterns that are then applied quickly and easily to behavioral events. They hypothesized that attributional schemas operate as selective mechanisms that direct acquisition of new information and facilitate inferences drawn from available knowledge. Encountering even a single element of a schema primes the rest of the schema, thus making it more likely that judgments consistent with the schema will be facilitated. The directness of response latency methodology allowed Zuckerman and Evans to infer that attributions were being made through a schematically-facilitated process.

A related line of research examines the tendency to attribute causes of behavior to the person instead of to the situation a phenomenon called the correspondence bias. Arguing that person versus situation judgments are not strictly automatic, Bassili \& Racine (1990) used response latency measurement to help explain this process. The automatic viewpoint proposes that vividness and salience of an actor's behavior directs attention to the actor and makes person attributions more likely (Gilbert \& Krull, 1988; Gilbert, Krull, \& Pelham, 1988). Since person attribution is considered automatic, this theory does not predict that making person judgments will facilitate subsequent situational attributions (or vice-versa). In contrast, Bassili and Racine (1990) promote the "concurrent judgment" view claiming that bias in person-situation judgments is not automatic. Instead, they claim person attributions are easy to apply, which allows cognitive resources to be allocated elsewhere. They postulated that person (versus situation) judgments are simpler to make because a person's behavior is obviously tied to 
the individual, but situations are not as clearly interpretable. Bassili and Racine (1990) observed that making a person attribution facilitated a subsequent situational attribution, but making a situational attribution did not facilitate subsequent person judgments. Response latency measures demonstrated that less processing was required for the subsequent situational, as opposed to person, attributional judgments showing that person attributions are cognitively simple and enable processing of situational components of the attribution.

Bassili and Racine's use of response latency is unique in being used to distinguish between two process models of the correspondence bias. While both models predicted similar outcomes, each model assumed differing underlying processes. Response latency allowed a comparison of these models under two conditions, where one model predicted differences in response time, and the other predicted no such differences. Attenuated responding was thus used to infer that extra cognitive processing occurred in one condition but not the other.

Response latency measurement in attributional research has helped to clarify the cognitive processes underlying attributional judgments. Studies of information processing for attributional judgments use response latency to identify both the content of attributional representations and to determine how those representations might facilitate processing of incoming information (Smith \& Miller, 1979; Ferguson \& Wells, 1980; Zuckerman \& Evans, 1984; Bassilli \& Racine, 1990). Mechanisms like these are uniquely tapped by response latency methods that can allow inferences about the structure and processing efficiency of underlying mental representations. 


\section{Impression formation}

Researchers interested in impression formation investigate how people come to ascribe personality attributes to others. The use of response latency in this area of research has provided insight into the manner mental representations shape perception and judgment of others' behavior. Impression formation researchers typically focus on a perceiver's judgment to examine how previous learning, situational context, personality variables, and goals affect the impression that is formed. The content of the judgment itself tells us little about the processes that produced it since differing cognitive processes can produce the same output. Response latency measures avoid the challenge of accessing mental representations through a perceiver's conscious judgments because of their unobtrusive nature. As a consequence, response latencies can be the probe that reveals the mechanism underlying the more visible output in the form of a judgment or impression.

Initial uses of response latency in impression formation research investigated how impressions are stored in memory (Park, 1986). Park assumed that traits that had previously been incorporated into one's impression could be accessed directly and quickly. On the other hand, traits that were not already represented in memory would need to be computed from past behavior or other previously ascribed traits. As a consequence, non-represented traits would take longer to categorize. By obtaining a measure of response latency, Park observed that traits that had been linked to the target in prior sessions were judged more quickly than traits that had not previously been linked to the target. Response latencies were then used to infer that people store trait 
representations in memory, and that trait information that is not present must be computed from other stored information.

Park suggested that central traits would be more strongly associated with the target individual than would peripheral traits, such that activation of the target would likely also activate central traits. Thus, the centrality of a trait to a target's identity could be measured by how fast the perceiver ascribed the trait to the target. In support of this hypothesis, Park observed that central traits were judged more quickly than peripheral traits. Park's use of response latency led her to the important conclusion that traits are linked to targets in memory, and that the strength of these links is moderated by the centrality of the trait to the target's perceived identity.

Theories about how information is organized in memory have led to various hypotheses about the manner in which exposure to a target individual's behavior is translated into a complex ascription of traits to the target (Anderson, 1987). Response latency measures provide valuable insight into how that translation occurs. Stewart, Doan, Gingrich, \& Smith (1998) proposed that once an individual has connected a particular behavior to a particular trait (e.g., "if Joe gets an A on the exam, then Joe is intelligent"), this connection would facilitate future trait ascription for that same behavior. In addition, the more specific the connection (i.e., the same person is performing the behavior), the faster the trait should be ascribed. Stewart et al. (1998) used response latency to infer the existence of a connection between a particular behavior and an associated trait. Participants were presented with behaviors performed by particular individuals (e.g., Joe got an A on the exam), and judged whether or not the behavior was indicative of the associated trait (i.e., intelligence). Subsequently, 
participants were asked to make trait judgments about various behaviors. As predicted by Stewart et al. (1998), participants categorized previously judged behavior more quickly than new behaviors. Latencies were most strongly facilitated when the same individual performed the behavior. Response latency measurement thus illustrated not only the existence of connections between particular behaviors and trait formation, but also the implications of these connections for future processing.

Although the link between behaviors and associated traits seems robust as indicated by Stewart et al.'s findings, the subsequent link between traits and their ascription to particular individuals is less clear (Hamilton, 1988; Srull \& Wyer, 1989; Trope, 1989; Ulemann \& Bargh, 1989). Using a response latency procedure, Whitney, Davis, \& Waring (1994) demonstrated that although traits could be spontaneously activated by a behavior, these traits would not necessarily be ascribed to the target individual. Differences in response latencies indicated that processing of behavioral information about a target individual was disrupted due to interference of competing information. Whitney et al. argued that the trait activation could be automatically ascribed to the behavior itself (i.e., "That was a dumb thing to do."), instead of being ascribed to the individual (i.e., "He is a dumb person."). To investigate this possibility, participants read a paragraph consisting of four sentences. One group read with an explicit goal of forming an impression of the actor, whereas other groups were given goals unrelated to forming an impression. For all groups, paragraphs began with a sentence implying a trait based on a particular behavior (e.g., a generous act), and the final sentence of the paragraph described a behavior inconsistent with the original (generous) behavior. Participants who did not have the explicit goal to form an 
impression did not evidence any disruption in reading time due to the inconsistent behavior description. In contrast, participants who did have the explicit impression formation goal read more slowly when confronted with the inconsistent information. Extended response time indicated that contradictory information may have led the reader to engage in more substantive cognitive processing to reconstruct a mental representation of the actor. In this study, response latency indicated the magnitude of 'disruption' incurred by capturing attention resources and effortful processing toward an inconsistent stimulus. Using response latency, Whitney et al. (1994) were able to infer that encoding of behavioral information does not necessarily lead to trait ascription, by demonstrating conditions under which this process does not occur.

The above studies demonstrate the role played by response latency in the formation of impressions. We move now to consider an alternative use of the methodology within this field; the use of response latency to demonstrate that preexisting mental representations also affect the way we perceive others.

Perceptions of others are shaped by memory. People tend to be described by the features that distinguish them from others. For example, a woman's gender is more likely to be mentioned if she is doctor than if she is a nurse because being female is considered more distinctive among doctors than among nurses. The non-normative elements of an individual seem to 'pop out' as salient characteristics of the individual. In research examining this phenomenon, response latency was used to measure the accessibility of particular features of individuals that differed in salience.

Zarate \& Smith (1990) argued that the primacy of non-normative features are a product of their organization in memory. They argued that in perceiving Black males, the 
racial category 'Black' is non-normative while the gender category 'male' is normative. If primacy of non-normative categories exists at the level of memory, categorization of Black males as 'Black' should occur more quickly than categorization of Black males as 'male'; a prediction confirmed in their experiments. Using the same response latency procedure as Zarate and Smith, Stroessner (1996) provided a more extensive explanation of the effect of memory on the perception of social features. Targets who were members of non-normative categories were classified more quickly when participants classified on the basis of the non-normative category. However, when the classification task required that the non-normative category be ignored, response times to members of non-normative groups were inhibited relative to normative group members. These response latency data suggest that non-normative features have some cognitive precedence over other features perhaps because such features are highly accessible elements in memory. Here, response latency measurement revealed that features are hierarchically ordered in memory, and that non-normative features have special status in the perception and categorization of individuals.

Response latency has also been used to demonstrate that individual differences can alter the incorporation of new information about group members. In the study described earlier by Stewart et al. (1998), high prejudiced persons were more likely to generalize behaviors performed by one minority member to other members of the same group than were low prejudiced persons. Here, response latency served as a measure of 'generalization' to other group members. High and low prejudiced Caucasian-American participants made initial stereotypic judgments of an unknown African-American's behavior. Later, participants made judgments of the same behavior performed by either 
the same African-American or an unknown African-American. Low-prejudiced participants showed strong facilitation for judgment of the behavior performed by the same actor, but weaker facilitation for the behavior when a different actor performed it. High-prejudiced participants, on the other hand, showed strong facilitation for both the same actor and a different actor. Response latency measures indicated that personality differences (prejudice) can influence the interpretation of a behavior and the storage of that behavior in memory. For high prejudiced participants, a single incident of a behavior is likely to be stored in memory as representative of the whole group. For low prejudiced participants, a single incident of a behavior is likely to be stored in memory as related only to the actor that performed the behavior.

While personality differences chronically influence how impressions are formed, short-term goals can temporarily affect the impression formation process. A study by Thompson, Roman, Moskowitz, Chaiken, \& Bargh (1994) used response latency to demonstrate that having a goal to form accurate impressions could attenuate the effects of covert primes. Earlier research had demonstrated that priming a trait category (e.g., hostile) can influence judgments of ambiguous behaviors, and this effect was even stronger when participants were unaware of the prime (Moskowitz \& Roman, 1992; Srull \& Wyer, 1979). In Thompson et al.'s study, participants were implicitly primed with a trait category and then asked to read a description of a person. When participants were given a goal to be accurate, reading times were longer and effects of primed constructs were attenuated, a finding taken to indicate more careful and systematic processing. This application of response latency assessed motivation to be more accurate. 
Applications of response latency in impression formation research cover three general categories: (1) examining the structure of mental representations, (2) exploring the effect of memory on perceptions of others, and (3) measuring the motivation to be accurate. Response latency measurement has elucidated associative links that form in memory between behaviors, traits, and individuals during the development of impressions (Park, 1986; Stewart et al., 1998; Whitney et al., 1994). Response latency has also been used to show the opposite process. Memories, once formed, can influence the processing of new information (Zarate \& Smith, 1990; Stroessner, 1993). Finally, motivation or magnitude of cognitive processing is indicated by the time spent reading a passage or forming an impression (Thompson et al., 1994). Response latency measures have been profitably applied to these questions because response latency serves as a relatively direct measure of cognition.

\section{Interaction}

How one interacts with others in the social environment defines humans as social animals. Cooperation, competition, conformity, collective effort, and avoidance are characteristics of interactions that researchers have examined using response latency methodologies. In general, response latency has been used to infer cognitive effort directed toward an interpersonally relevant outcome. This general measure of cognitive effort has been used to evaluate cooperative, competitive, and avoidant tendencies in interpersonal situations.

Psychologists interested in people's cooperative and competitive behavior have used a well-known paradox called the "prisoner's dilemma." The prisoner's dilemma 
represents a situation where benefits for the group are placed in counterpoint to benefits for the individual. Cooperation of both individuals maximizes the collective outcome. If one individual in the pair defects from the cooperative decision, the defector reaps greater rewards than when cooperating, and in this case, the individual that chooses to cooperate receives nothing. If both individuals defect from cooperation, the rewards are paltry. Herein lies the heart of the prisoner's dilemma. While the best outcome for both occurs when they cooperate, it is to the individual's advantage to defect when the other cooperates and reap the rewards.

Knox and Douglas (1971) applied response latency to the prisoner's dilemma to evaluate the amount of cognitive effort invested in situations where the rewards were minimal (cents) versus substantial (dollars). Participants in the substantial reward condition deliberated longer before making a decision to cooperate or defect than individuals in the minimal reward condition. Knox and Douglas reasoned that longer deliberation was indicative of greater cognitive effort; specifically, effort devoted to predicting the other participant's decision. In this early study using response latency, the author's expressed little interest in the nature of the cognitive processing itself. Response latency was used to infer only that more processing had occurred in conditions where rewards were high than in conditions where rewards were relatively low.

In a more recent study, response time was used to examine the power of normative influences on decision-making. Normative influences describe the tendency to conform to the positive expectations of others in order to maximize the likelihood of positive social outcomes (Deutsch \& Gerard, 1955). Campbell and Fairey (1989) used response latency to measure the degree of uncertainty or conflict experienced by 
participants in making decisions anomalous to the group. They observed that normative influences had stronger effects, as the norm itself was increasingly unbelievable. That is, when the normative response could be construed as correct, response times were relatively quick. However, when the norm was clearly wrong, response times were slower. The authors explained that confrontation with a norm that was clearly wrong increased the conflict between motives to be correct and motives to be liked. Although the ultimate decision to agree or disagree with the group varied as a function of group size, response time did not, suggesting that even though the decision itself was affected by the size of the group, the internal conflict regarding whether to conform to the norms persisted irrespective of the group size. In this study, response latency indicated the magnitude of the conflict between the desire to be right and the desire to be liked. Using response latency as a measure of internal conflict was particularly appropriate in this study. A self-report measure would likely alert participants to the potential influence of the group and the power of normative responses. This awareness would likely impact participant's reactions to the conflict scenarios. With response latency, participants were not alerted to the primary variables of interest in the situation. As an unobtrusive measure of motivation, response latency did not influence the participant's decision making process allowing for a more 'natural' response.

Response latency has also been used to measure motivation in an interpersonal context. People tend to expend less effort working in group settings than working individually, even when task demands are identical. Popular theories blame this 'social loafing' on a decrease in the sense of personal responsibility for outcomes. However, since much of human behavior (especially in work settings) is group-based, there is clear 
motivation to minimize social loafing. A recent study used a response latency task to examine factors that might minimize social loafing (Hocksema-van Orden, Gaillard, \& Buunk, 1998). Participants were required to work for 20 hours, almost continuously, in either a group or individual context. Response latency was used as a measure of motivational decline over the 20 hour period by measuring repeated performance on a simple categorization task (Boer, 1995). In general, participants' response times slowed due to fatigue over the 20 hours. However, participants for whom personal responsibility was emphasized demonstrated far less decline in performance over time than participants who did not feel personally responsible. In addition, if performance feedback was expected to be publicly shared, decrements in performance over time were significantly attenuated. Here, response latency indicated the magnitude of decline in motivation over time. Use of this measure revealed that effective deterrents to social loafing included an emphasis on the connection between individual effort, and expectation of publicly shared performance feedback.

Social loafing, conformity and cooperation are all elements of the behavior of people operating in concert with others. However, there are many situations where humans attempt to avoid interaction. Interpersonal avoidance is characterized by a variety of non-verbal behaviors. Avoiding eye contact, turning away, feigning sleep, or leave uncomfortable interpersonal situations are indicators of the quality of social interaction and determinants of the future of such interaction. Many avoidance behaviors are measurable with response latency techniques.

In an interesting study by Greenbaum and Rosenfeld (1978), unwitting participants were stared at in order to induce interpersonal avoidance. In this study, a 
male experimenter sat at the corner of an intersection a distance near or far away from the curb. The experimenter then stared at (or didn't stare at) drivers who approached and stopped at the intersection. ${ }^{4}$ The length of time subjects stared back at the experimenter was recorded. Female participants who were stared at by the male experimenter spent less time staring back than did female participants who were not stared at. This effect did not occur for males. The authors suggested that females felt a stronger desire to avoid interaction with the staring stranger relative to the non-staring stranger. Also, departure speed, or the time taken to leave the intersection after beginning to move, was measured. An increase in interpersonal avoidance was characterized by a decrease (speeding up) in departure time from the scene (see also Ellsworth, Carlsmith, \& Henson, 1972). Drivers who were stared at crossed the intersection more quickly than did drivers who were not stared at. Thus, participants who were stared at exhibited strong interpersonal avoidance by leaving the intersection quickly. This unusual application of response latency allowed inferences about participants' motivation to remove themselves from an awkward interaction with strangers. Like other studies in the area of interpersonal interaction, Greenbaum and Rosenfeld exhibited little interest in the what participants were specifically thinking during these episodes. Rather, they inferred that the manipulation induced a general set of cognitions that motivated interpersonal avoidance.

The studies reviewed in this section emphasize the use of response latency to infer subjects' motivation in interpersonal contexts. Participants are motivated to be rewarded (Knox \& Douglas, 1971), be liked (Campbell \& Fairey, 1989), perform well when personally responsible (Hocksema-van Orden et al., 1998), and to avoid uncomfortable interactions (Greenbaum \& Rosenfeld, 1978). Use of response latency for motivational

\footnotetext{
${ }^{4}$ In the staring condition, data was only recorded if eye-contact was made with the driver.
} 
purposes is distinct from its use as a measure of cognitive processing. In using response latency as a measure of motivation, no direct measure of cognitive processing occurs in the experimental design. Instead, response latency measurement compares behavioral responses in different scenarios. In this way, no direct conclusions are drawn of the nature of the cognitive processing. Response latency is used only to infer that participant behavior is indicative of motivational tendencies to act or not act.

Response latency assesses motivation very differently from self-report measures. In self-report experiments, motivation is assessed by explicitly asking participants for their feelings of motivation. In this set of studies, motivation was defined as either the amount of time engaged in an activity, or how quickly one tried to leave an uncomfortable situation. In these experiments, it is not clear that motivation was consciously experienced - perhaps for this reason, response latency served as a valuable index of behavioral motivation and avoidance.

\section{Close relationships}

A literature using response latency to examine a variety of issues related to intimate relationships is growing fast. Perceptions of the other and interaction styles are important variables for quality and content of close relationships. Mental representations of coping styles and interaction goals are presumed to guide one's thought processes in important aspects of close relationships. Response latency is generally used to make inferences about mental representations of the self, or of interaction goals and coping styles. Also, using response latency, researchers provide evidence that intimate partners are actually integrated into one's representation of the self. 
Self-other confusion in close relationships. It is not uncommon to hear someone say of his or her partner, "I feel like she is a part of me." Research utilizing response latency suggests that, even at the level of memory, partners may confuse their own identity with that of their partner. Aron and colleagues (Aron, Aron, Tudor, \& Nelson, 1991; Aron, Aron, \& Smollan, 1992) argue that one aspect of a close relationship is the inclusion of the other in the representation of the self. Aron et al. (1991) demonstrated this self-other integration using a response latency technique popularized by Markus (1977) to examine the self-concept. Participants observed traits on a computer screen and judged whether the trait was representative of the self ('me') or not ('not me'). The speed with which one responds to a trait was taken to be indicative of the strength of association between that attribute and the self. Traits that are classified quickly are assumed to be more strongly associated with the self than traits that are classified more slowly. Aron and colleagues observed that traits descriptive of both the individual and his or her partner were categorized quickly. ${ }^{5}$ However, traits that were not shared with the partner were categorized more slowly. Aron and colleagues explained that participants responded more slowly to non-shared traits because of identity confusion - participants' self-identity included a representation of their spouses. ${ }^{6}$ As a consequence, responses to non-shared traits are slower than responses to shared traits.

Overlap of others' traits into the representation of the self is not limited to intimate partners. Smith and Henry (1996) demonstrated similar non-shared trait confusion with one's in-group (e.g., fraternity brothers). More generally, traits that are

\footnotetext{
${ }^{5}$ Participants made judgments of the self-relevance of the traits. They were not aware of any connection between this study and their spouse.

${ }^{6}$ A control comparison of shared/unshared characteristics with another person clarified that the results were not due to availability or desirability of the shared traits.
} 
distinctive to the self are recognized more slowly than are traits shared with others (Mueller, Ross, \& Heesacker, 1984; Ross, Mueller, \& de la Torre, 1986). These studies used reaction time to shed light on the mental representation of the self in memory. In these cases, response latency assessed the degree to which representation of the self was intertwined with a relevant other. They demonstrated that the self is not an isolated representation independent of other individuals or groups relevant to the self. Individuals that we interact with frequently, or groups that are important to our identity, cognitively become a part of the self.

Activation of outcomes, goals, and coping styles in the interpersonal context. Interpersonal expectations, goals, and coping styles are typically measured through conscious self-report methodologies. However, these interpersonal attributes also have highly developed representations in memory, and have been effectively investigated using response latency methods.

Baldwin, Fehr, Keedian, Seidel, \& Thompson (1993) demonstrated that automatic activation of perceived relationship outcomes varied as a function of adult attachment styles (secure, anxious-ambivalent, avoidant). Using response latency as the primary dependent variable, they demonstrated that secure individuals responded more quickly to positive outcome terms (e.g., care), while insecure individuals responded more quickly to negative outcomes (e.g., hurt) in a trust-related context. Response latency indicated the magnitude of activation for positive or negative outcomes following priming of a trustrelated scenario. The authors explained that secure individuals have an automatic tendency to expect that trust-relevant scenarios will have positive outcomes. Conversely, insecure individuals have an automatic tendency to expect that trust-related scenarios will 
have negative outcomes. Response latency was used to infer the degree to which positive or negative outcomes were part of an individual's primary response to trust-related information.

Automatic activation of trust-related goals and coping styles may also vary by attachment style (Mikulincer, 1998). Three relationship goals: 'intimacy', 'control', and 'security' were primed with trust-related sentences. Response latency measured the magnitude of association between the trust-related scenarios and each of the relationship goals. Faster categorization of the goals indicated a stronger association with the trustrelated prime. For secure persons, trust-relevant primes activated the goal of 'intimacy' more strongly than goals of 'control' or 'security.' For anxious-ambivalent persons, 'security' and 'intimacy' goals were both activated in a trust-related context. For avoidant persons, 'control' and 'intimacy' goals were activated in the same context. Mikulincer reasoned that automatically activated goals could guide immediate responses to trust-relevant situations, with variations in automatic activation suggesting that different goals will be elicited in trust-related contexts depending on the individual's attachment style. Similar results were observed for automatic activation of coping styles (e.g., 'talk,' 'worry,' or 'escape') in trust-related contexts (Mikulincer, 1998). Response time in this set of studies measured the magnitude of activation of a goal or coping-style in a trust-related situation. Response latency measures demonstrated that an individual's trust-related goals and coping styles are automatically activated and have a cognitive advantage over other, perhaps more well-adjusted, interaction styles.

Strong conclusions can be drawn with response latency measures when individual differences in response time are identified. Baldwin et al. (1993) and Mikulincer (1998) 
provide excellent demonstrations that individual differences on variables such as attachment style can predict differences in the mental representations of expectations, goals, or coping responses. Response latency measurement has shown that observed differences between groups are more than simple differences in the conscious interpretations of interpersonal situations. Rather, attachment styles can shape the way information is organized and maintained in memory.

Application of response latency measures in close relationships research has enabled investigation of underlying mental representations relevant to intimate relationships. Response latency was used to identify the overlap between the self and partner in memory. Over time, the representation of the self integrates self and partner. Also, response latency identified a relationship between attachment styles and automatic activation of outcomes, goals, and coping styles relevant to close relationships. Response latency methods were used to identify personality factors that were predictive of differences in representations at the level of memory. These investigations imply that mental representations of anticipated outcomes, goals, or coping styles might influence evaluations of intimate interactions. The mental representations of interaction styles, and the integration of the self and partner in memory, may be important guides to everyday behavior in intimate relationships. The next section begins with a review of response latency research on the self. Here we review research aiming to more fully understand the underlying structure of the self in memory. 


\section{Intrapersonal Processes}

\section{Self}

Although most people have intuitive notions about what the self refers to, a concrete description of the self is difficult to articulate. Individuals frequently believe they have a clear view of themselves when they turn their attention inward. Researchers relying on introspective judgments about the self have gained important insights into the perception of the self. If the goal is to measure the mental representation of the self, such an investigation of the self becomes possible through the use of response latency measures. This methodology has allowed researchers to tap the mental representation of the self without relying on the ability to accurately introspect. Response latency measures in research on the self have investigated the cognitive structure and processing of self-relevant information. In particular, response latency research has emphasized that the self may be much more than what is grasped through conscious introspection.

The mental representation of the self. A response latency task developed by Markus (1977) has been widely used in research on the self. Participants classified traits as either self-identifying ('me') or not self-identifying ('not me'). The speed that participants could classify traits as 'me' or 'not me' was taken as an indicator of the strength of association between the trait and the self. Markus' work is premised on the assumption that traits closely associated with the self will be highly accessible when the self has been activated, and will thus be categorized quickly. Traits not associated with the self will be less accessible, and thus will not confer an advantage in response latency. Studies have applied this straightforward response latency procedure to investigate a variety of issues about the self. 
For example, Turner (1978) investigated whether individual differences in social anxiety would affect the latency of ascribing socially desirable or undesirable traits to the self. Turner observed that individuals who were high in social anxiety were slower to categorize traits as me or not me, and especially slow to categorize undesirable traits (as compared to individuals low in social anxiety). The additional cognitive processing evidenced by the highly socially anxious group during trait self-ascription was captured using response latency. Turner reasoned that highly socially anxious individuals are more concerned about the social implications of their responses, and so spend more time considering the consequences of their responses, as compared to less anxious participants.

Differences in cognitive processing about the self can also be observed by comparing individuals high and low in self-esteem. Baldwin and Sinclair (1996) examined the relationship between conditional thoughts and self-esteem. For some individuals, interpersonal acceptance is perceived as highly conditional (e.g., "They will only like me if I succeed."), whereas others assume that their acceptance is more unconditional (e.g., "They will like me whether or not I succeed."). Baldwin and Sinclair anticipated that individuals with low self-esteem would believe that acceptance was more conditional than would individuals with high self-esteem. To test this hypothesis, they employed a lexical-decision task designed to reveal associations between success/failure primes and acceptance/rejection targets. The lexical-decision task operates on the principle that exposure to a relevant prime will make associated target words more accessible. Response latency in this study reflected the amount of time necessary to judge whether the target was a word. Thus, variations in the latency to judge the target as 
a word or non-word indicated differences in the strength of association between the semantic meanings of the primes and the targets. For low self-esteem subjects, success primes speeded processing of acceptance targets, and failure primes speeded processing of rejection targets. No such relationship was observed with high self-esteem subjects. This finding supported Baldwin and Sinclair's hypothesis that low self-esteem subjects link concepts of acceptance to conditional outcomes.

In a follow-up study, Baldwin and Sinclair (1996) demonstrated similar effects by manipulating esteem-relevant feedback, rather than comparing chronically low selfesteem subjects to chronically high self-esteem subjects. In this study, they used response latency to reveal that the relationship between trait self-esteem and perceptions of conditional acceptance can also be induced intra-individually, following esteem-related priming. This study nicely demonstrated that automatic cognitive processing about the self is a product of both stable individual differences and dynamic situational contexts.

Unlike Turner, and Baldwin and Sinclair's focus on the relationship between the self and trait characteristics, other researchers have emphasized a relationship between the self and state-dependent variables. Paulhus and Levitt (1987) investigated the impact of state-dependent affect on the interaction between social desirability and responding about the self. They proposed that affective arousal would induce an 'automatic egotism,' or a stronger automatic liking for the self. Using the popular Markus (1977) design, response latency was used to infer the strength of association between a target trait and the self. Adding a unique twist to previous designs, they had a distractor word appear each time a trait appeared for classification. The distractor terms were either neutral or affectively-loaded. Paulhus and Levitt observed that socially desirable 
responses were accelerated in the presence of affective stimuli, while socially undesirable responses were inhibited. Using response latency, they demonstrated the important influence of state-dependent affect on cognitive processing. More specifically, they showed that automatic cognition about the self could be induced to be more 'selfish' by transient affective information.

The studies reviewed in this section thus far demonstrate that one's representation of the self can be affected by both transient and stable affective variables. We now turn our focus away from the ways the individual affects his or her representation of the self to examine the effects of in-group identification on representation of the self.

Identification with one's group affects mental representation of the self. Social Identity theory posits that an individual's group memberships become integrated into representations of the self, and consequently affects cognition and behavior (Smith \& Henry, 1996). Smith and Henry (1996) demonstrated this effect, using the response latency technique developed by Aron, Aron, Tudor, and Nelson (1991; see description in section on close relationships). Participants in Smith and Henry's study judged traits as 'me' or 'not me' more quickly when their in-group shared the trait, and more slowly when the in-group did not share the trait. The authors interpreted this finding to suggest that self-identity is defined, in part, by one's group memberships. Response latency measurement thus revealed that the mental representation of the self is integrated in memory with relevant other groups.

In a related study, Mills (1983) investigated how an individual's gender identification affected processing of information about the self. Feminine women categorized the self-relevance of feminine traits more quickly than they categorized 
masculine traits. In contrast, masculine men categorized the self-relevance of masculine traits more quickly than feminine traits. Androgynous men and women demonstrated no differences in processing time for masculine and feminine traits. Based on these findings, Mills argued that sex-typed individuals cognitively organize the world in gender terms. This organizational structure then facilitates processing of gender-related items, especially when evaluating their relation to the self. Response latency measurement allowed Mills to infer that in-group characteristics (in this case, sex typing) affected processing of trait information about the self.

Response latency measurement has been particularly useful at identifying the underlying mental representation of the self, and how information processing about the self can be contingent on the structure of that representation. Response latency has enabled researchers to infer that the mental representation of the self is affected by both state and trait variations (e.g., anxiety and esteem), and by group membership. Use of response latency to examine the underlying representations of the self has allowed researchers to begin to understand the structure and malleability of this elusive construct, and has allowed for the examination of self-representation above and beyond introspective techniques.

\section{Stereotypes}

Stereotypes involve the ascription of individual personality traits to groups (i.e., elderly people are poor drivers). These generalizations can guide our thinking and judgments about members of particular groups, and can even color the way we encode perceptions of others behavior (see Fiske, 1998 for a review). Response latency measurement has been used to demonstrate that stereotypes exist in memory, that they 
can be activated automatically outside of one's control, and that stereotypes can affect one's behavior without conscious awareness.

Stereotypes exist at an automatic level of cognition. Dovidio, Evans, \& Tyler (1986) studied the automaticity of stereotypes. Participants were primed with race categories, then judged positive and negative target words that were stereotypic of either Blacks or Whites. The judgment involved deciding whether the target stereotype could "ever be true" or was "always false" of the primed category. Response latency measured the strength of association between the race categories and the stereotypical items. Race primes facilitated automatic responses to stereotypical items, independent of whether or not the participant had consciously endorsed or rejected the stereotypes. These response latency results led to the important finding that, irrespective of conscious endorsement of racial stereotypes, associations between racial groups and beliefs about them exist at the automatic level.

Dovidio and colleagues (1986) found that these automatic stereotype judgments were not always consistent with conscious stereotype judgments. Further support for this apparent desynchrony was evident in an investigation of automatic gender stereotypes (Banaji and Hardin, 1996). Banaji and Hardin found that gender pronoun targets were judged more quickly when primed by a stereotype-consistent item (e.g., doctor primes 'he', nurse primes 'she') than by a stereotype-inconsistent item. Surprisingly, this effect was observed regardless of (a) the participant's awareness of the prime-target relationship, or (b) the participant's explicit beliefs about gender stereotypes. Participants who rejected gender stereotypes at the conscious level exhibited the same level of automatic stereotyping as participants who endorsed explicit gender stereotypes. 
Response latency measurement revealed effects independent from those observed with conscious report measures, suggesting that automatic stereotypes measure thought processes that may be distinct from traditional self-report measurements (Greenwald \& Banaji, 1995). Although a full understanding of the relationship between these two measures of stereotyping is not yet clear, response latency techniques have led to the important finding that automatic and controlled components of stereotyping may not be products of the same underlying cognitive system.

Researchers have now begun to assess how these independently functioning systems of stereotyping differentially influence judgment. Blair and Banaji (1996) investigated the degree to which automatically evoked gender stereotypes could be consciously controlled. In a design similar to the Banaji and Hardin (1996) paradigm, Blair and Banaji varied the time between presentation of the prime and target. In one condition, automatic stereotyping of the target terms was elicited when the prime and target were presented with only a brief pause between them $(300 \mathrm{~ms})$. In a second condition, participants were told to expect that targets would be counter-stereotypic to the primed gender. Participants' automatic stereotyping diminished when they were expecting counter-stereotypic targets, but their stereotyping did not vanish. However, when the prime and target were separated with a relatively longer pause (3000ms), a counter-stereotypic expectation completely reversed the response times. Paradoxically, participants responded more quickly to targets stereotypically inconsistent with the primes than to targets consistent with the primes. Blair and Banaji explained their findings by proposing that the longer pauses led to conscious processing which altered task performance. Thus, participants were able to control their stereotype expression, but 
only the more conscious variety. In the condition with shorter pauses, little or no conscious processing interfered with the automatic evocation and expression of the stereotype association. Response latency allowed researchers to demonstrate that the presence of stereotypes in memory is not related to the conscious endorsement of those stereotypes. Stereotypes are activated spontaneously and automatically, and conscious efforts are critical in efforts to attenuate expression of the negative effects of automatic stereotypes. The social implications of this finding for changing negative stereotypes may be tremendous, and this increased understanding has been importantly facilitated through the use of response time methodology.

Implicit activation of stereotypes affects behavior. Response latency measures have revealed that stereotypes exist at the level of memory and can be activated automatically. However, the previous studies do not clarify when implicit stereotypes might affect behavior. A series of experiments by Bargh, Chen, and Burrows (1996) dramatically demonstrated that stereotypes affect behavior even when the stereotypes were activated without conscious awareness. In these studies, response latency was used as a behavioral dependent measure, rather than as a measure of representation in memory (as in studies described earlier). In the first experiment, Bargh et al. (1996) used a scrambled sentence task to prime either politeness or rudeness by imbedding key words into the sentences. When participants finished the task, they were told to inform the experimenter that they were done. After completing the task, participants would find the experimenter apparently talking to another subject (who was actually a confederate). Response latency was used to assess how long the participant would wait before interrupting the experimenter's conversation. Individuals primed with rudeness words 
interrupted the experimenter more quickly and more frequently than individuals primed with politeness words. Thus, the latency between finishing the task and interrupting the experimenter captured actual behavioral differences resulting from this remarkably subtle prime.

In a second study, Bargh and colleagues used another scrambled sentence task to prime participants with either an elderly or a neutral stereotype. Upon finishing the priming task, participants were then thanked and excused. A confederate surreptitiously measured the amount of time it took participants to walk down the hallway to leave the experiment. Astonishingly, participants who were primed with the elderly stereotype walked more slowly down the hall than participants who were neutrally primed. This finding is especially surprising given that the prime contained no direct reference to slowness. Response latency measurement actually demonstrated the impact of the elderly prime on motor behavior. These effects were observed despite the fact that participants were not aware of the priming. In fact, even after participants were fully debriefed about the purpose of the study, they all denied that the primes could have affected their behavior.

Response latency has further delineated the processes underlying implicit stereotypic judgments by demonstrating differential effects on behavior depending on the nature of the prime (Dijksterhuis et al., 1998). Specifically, Dijksterhuis et al. (1998) demonstrated that priming exemplars as opposed to traits (like in the Bargh et al. studies) lead to a contrasting behavioral outcome. They presented half of their subjects with a trait elderly prime (identical to Bargh et al.,1996), and the other half with an exemplar elderly prime (in this case, the Queen of Holland). They found that presenting the trait 
prime replicated Bargh et al.'s result (i.e. slower walking), but presenting the exemplar prime elicited a contrary effect. Specifically, participants primed with an elderly exemplar actually walked faster than control subjects did. The authors explained that priming the elderly exemplar induced a comparative process where the participants' comparative youthfulness was activated. The differential findings for trait versus exemplar primes demonstrates the remarkable specificity with which response latency can capture the effects of implicit processing of stereotypic information on behavior.

These creative applications of response latency help to demonstrate that subtle primes need not reach conscious awareness to affect behavior. Indirect invocations of stereotypes or traits can slow down spry youth, or make the docile young college student impatient and demanding! Response latency measures have furthered stereotyping research by illustrating that stereotypes exist even when consciously unexpressed, can be activated automatically, and can subtly affect behavior. While it is easy to dismiss societal stereotypes as external and irrelevant to the self, response latency has revealed that these same stereotypes may in fact be instantiated in the thought systems of all humans. The demonstrated effects of these implicit stereotypes on our own behavior cannot be casually dismissed.

\section{Mood and affect}

The study of cognition has dominated psychological research for many years, leaving emotions and motivation, the other two components of the psychological triumvirate, without serious attention until recently. In its short scientific history, emotion research has become a serious and exciting field. In fact, the recent edition of 
the Handbook of Social Psychology (Gilbert, Fiske, \& Lindzey, 1998) included a chapter on emotions for the first time (Zajonc, 1998). In affect research, response latency has primarily been used to demonstrate that affective information can be perceived at very brief presentation intervals, and that mood interacts with cognitive processing, even automatic cognitive processing.

Affective information can be subliminally perceived. There is growing evidence that humans are programmed to respond to affective stimuli both quickly and automatically, suggesting that affective information provides important cues that help us navigate our environment (Zajonc, 1998). The speed with which humans recognize pleasant and unpleasant facial expressions is remarkable (Neidenthal, 1990). Neidenthal (1990) used response latency to illustrate that affective information could be perceived in subliminal presentations, such that conscious perception of the stimuli did not occur. In their study designed to demonstrate implicit perception of affective information, they subliminally presented joyful and disgusted faces immediately before presenting pictures of cartoon characters. In a follow-up discrimination task, the same pictures were preceded by primes that were either emotionally congruent or incongruent with the original primes. Response latency was used to indicate whether an association between the cartoons and the affective information from the facial stimuli would be formed in the initial subliminal presentation. Neidenthal found that congruent primes did in fact facilitate processing of the facial stimuli, indicating that perception of non-verbal affective information can occur subliminally, and be encoded in memory.

Similar results were reported with affectively-laden words in a simultaneous dichoptic pattern mask experiment (Greenwald, Klinger, and Liu, 1989). The speed of 
reporting the valence of the target word was influenced by the affective nature of the prime. Affectively congruent primes facilitated cognitive processing of targets, whereas incongruent primes inhibited responding.

Two possible explanations exist for these response latency results. First, the affective primes may have primed associated ideas in memory, which then assimilated the target into the representation. Second, the affective primes may have momentarily altered the individual's affective state such that it became congruent with the prime, and subsequently influenced evaluation of the target. These competing explanations remain to be disentangled. Nonetheless, response latency methods have procured novel and convincing evidence that nonverbal affective information can be perceived and encoded outside of an individual's conscious awareness.

In these examples, response latency was used to examine the cognitive perception of affective information. We now have evidence though that processing in this arena is bi-directional. Other researchers have used response latency to examine the effects of mood on cognitive processing and judgment.

Mood effects on schematic processing. Different affective states are associated with different styles of cognitive processing. Happy moods are generally associated with heuristic processing, while sad moods are typically associated with careful and analytic cognitive processing (e.g., Bless \& Fiedler, 1995). Some theorists have proposed that this difference is due to motivation, such that sad subjects search carefully to enable mood repair while happy subjects do not want to be distracted from their happy mood. In contrast, other theorists prefer a processing capacity interpretation, suggesting that happy subjects have less processing capacity available, resulting in greater dependence on 
heuristics. Response latency measures can help us tease apart whether an individual is using slow, motivated processing, or simply relying on heuristics. Both theoretical camps agree that happy subjects use more heuristic processing which should be associated with quicker response times, while sad subjects use more substantive cognitive processing which should be associated with slower response times. Ultimately, response latency may help us distinguish between the different theoretical explanations by comparing cognitive processing in varied mood states.

Bless and Fiedler (1995) designed a series of experiments to show that mood can effect not only heuristics processing specifically, but also processing of knowledge structures more generally (e.g., scripts and schemas). Heuristic processing is an example of general knowledge structures, which allow efficient processing of incoming information, and thus require few cognitive resources. In one study, Bless and Fiedler had participants read a sentence that associated a trait with a target person (e.g., Joe is generous). Later, participants read a second sentence indicating whether or not the target person performed a behavior which was congruent with the initial trait. Response latency indicated the ease of processing new information about the target, which was either consistent or inconsistent with the earlier trait association. Latency measures demonstrated that sad subjects did not use the trait information from the first sentence, but instead responded to both congruent and incongruent information with slow, motivated processing. In contrast, happy subjects were faster at reading sentences containing consistent trait information (as compared to inconsistent information). Bless and Fiedler reasoned that happy subjects' facilitated responding to the consistent information occurred because reading the initial trait sentence had generated a schema- 
driven processing strategy, which could then easily be applied to the second (consistent) sentence. Response latency thus revealed differences in the degree of cognitive processing as a function of mood variations.

To further our understanding of the effect of mood on schematic processing, Forgas and Fiedler (1996) used response latency to investigate the effects of mood on inter-group discrimination. Research on discrimination has produced mixed findings; some studies have found that happy moods produce more discrimination than sad moods (Sinclair, 1988), while others find that sad moods produce as much discrimination (Stroessner \& Mackie, 1992). Trying to make sense of these inconsistent findings, Forgas and Fiedler (1996) suggested that the relationship between mood and discrimination is not direct, but is mediated by the personal relevance of the target group. They propose that when the personal relevance of the target group is low, happy moods are likely to produce more heuristic processing, thus increasing the likelihood of discrimination. In contrast, when personal relevance of the target group is high, happy participants are less likely to apply heuristic judgments.

A response latency dependent measure in concert with a behavioral measure allowed Forgas and Fiedler (1996) to test not only the hypotheses regarding discriminating behaviors, but also take a closer look at the processing strategies presumed to produce the effect. A minimal group task (where groups are created within the experimental session, rather than being pre-formed) was designed where participants were to divide resources among members of their group and another group. As they predicted, Forgas and Fiedler found that when group relevance was low, happy participants allocated resources more quickly and were more discriminating than control 
subjects, suggesting that these happy participants relied on heuristic processing. In contrast, when group relevance was high, the happy subjects did not make allocation judgments more quickly than controls did, nor did they allocate resources in a more discriminatory manner. Remarkably, the opposite pattern was observed for sad subjects. When group relevance was high, sad subjects exhibited longer response latencies when making allocation judgments and behaved in a more discriminatory manner than controls did, presumably because they were motivated to search for mood repairing information. In contrast, when group relevance was low, sad subjects responded with latencies similar to the control subjects', and did not behave in a more discriminatory manner. Response latency thus played a pivotal role in linking the process model proposed by the authors to actual experimental behavioral effects. By having both the behavior and the process model serve as dependent variables, Forgas and Fiedler could argue more confidently that their model effectively explains how mood effects intergroup discrimination.

Response latency has been successfully used to research both the perception of affective information (Neidenthal, 1990; Greenwald, et al., 1989), and the influence of mood or affective states on cognitive processing and judgment (Bless \& Fiedler, 1995; Forgas \& Fiedler, 1996). Examination of the processing strategies produced by particular moods are not easily available to conscious self-report, making reaction time an especially useful technique for this domain of research (Forgas \& Fiedler, 1996; see also Forgas, 1992, 1993, 1994).

\section{Attitudes}

Attitudes indicate favorable or unfavorable feelings toward social objects in our environment, and these evaluative responses ultimately guide our behavioral intentions 
(Eagly \& Chaiken, 1998). Investigations into the structure and automaticity of attitudes have been dramatically aided by response latency measurement because this methodology allows for examination of attitudes in memory, rather than relying solely on self-reflection of attitude judgments. More specifically, response latency measures have led to advances in identifying the importance of attitude accessibility for attitude expression, the representation of attitudes in memory, and the representation of attitudes that do not require conscious awareness.

Attitude accessibility. Fazio and his colleagues have articulated a model of attitude structure and its influence on behavior (Fazio, 1986, 1990; Powell \& Fazio, 1984). They argue that attitudes are object-evaluation associations in memory, and that the strength of the association will determine the likelihood that the attitude will be activated in the presence of the object. In other words, the stronger the object-evaluation association, the more likely the attitude will be spontaneously activated and will guide behavior toward the object. Response latency has played a critical role in garnering support for this model.

Fazio and colleagues hypothesized that highly accessible attitudes would be reported more quickly than less accessible attitudes (Powell \& Fazio, 1984). In an early experiment, Powell and Fazio (1984) examined this hypothesis by having participants report their attitudes toward particular social objects. In a subsequent task, response latency was used to measure the accessibility of these reported attitudes. As predicted, participants accessed attitudes that they had previously reported more quickly than attitudes they had not described earlier. 
Additional support for the link between attitudinal expression and accessibility was drawn from a study where participants evaluated paintings (Fazio, Blascovich, \& Driscoll, 1992). Again, response latency was used to demonstrate differences in ease of accessibility, thus demonstrating the robustness of the link to attitudinal expression and its potential application to all manner of attitude objects. Participants made comparative preference judgments about thirty paintings; ten which had been evaluated separately in a prior task, ten which had been previously judged for color content, and ten which had not been previously viewed. Latencies for preference judgments were shortest for paintings that had been previously evaluated and slowest for paintings that had not been viewed. Based on these findings, Fazio and colleagues concluded that attitude rehearsal improves attitudinal judgment efficiency and strengthens object-evaluation associations (see also Fazio, 1989; Fazio, Chen, McDonel \& Sherman, 1982). Response latency enabled the most direct test of the strength of the object-evaluation.

In addition to reflecting attitude strength, attitude accessibility has also been linked to attitude importance. Krosnick (1989) observed that participants made attitudinal judgments more quickly for items that had been rated as highly important to the individual, and more slowly for items judged to be less important. Building from this finding, Roese and Olson (1994) suggested that if an attitude is more accessible, then it will be judged to be more important. Thus, accessibility causally influences importance judgments. Following an accessibility manipulation using an attitudinal expression procedure, Roese and Olson observed that more accessible attitudes were judged more quickly and rated to be more important than were less accessible attitudes. Based on this 
result, they concluded that attitude accessibility, as measured by response latency, might function as a heuristic cue for attitudinal importance.

Attitude accessibility is influenced not only by the relationship of the attitude to the self (e.g., the perceived importance of the attitude to the individual), but also by individual difference variables. For example, attitude accessibility has been linked to personality traits, such as self-monitoring. Self-monitoring reflects the degree to which an individual considers situational variables and others' preferences before declaring his or her own attitudes or beliefs. High self-monitors match their attitudes and values to the situation and to others' views, whereas low self-monitors' attitudes are less situationally defined, and are thus perceived to be a more accurate reflection of the individual's underlying attitudes. Consistent with this hypothesis, Kardes, Sanbonmatsu, Voss, and Fazio (1987) observed that response latency for attitudinal judgments was faster for low self-monitors than for high self-monitors. Based on this finding, Kardes and colleagues claimed that low self-monitors held stronger object-evaluation associations in memory.

The studies described thus far in this section have been used to paint a clearer picture of the nature of attitude accessibility by outlining how it is influenced both by the attitude itself and by individual difference variables. However, researchers have also taken an alternative approach and used response latency to determine how effectively attitude accessibility can predict behavior. In a clever experiment conducted during the 1984 United States presidential election, Fazio and Williams (1986) asked participants whether they thought Reagan and Mondale would be good presidents over the next four years. Participants with shorter response latencies showed a stronger link between attitudes toward the candidates and actual voting behavior than did participants with 
longer response latencies. Thus, response latency demonstrated the predictive ability of attitude accessibility for actual behavioral outcomes (see also Bassili, 1995).

Implicit attitudes. It has been more than thirty years since the civil rights movement began, and Caucasian-Americans today generally report positive attitudes toward African-Americans. Yet, despite massive changes in the reporting of conscious attitudes toward African-Americans, racial bias is still an everyday part of American life. Expressions of these biases appear in more subtle forms today, but these biases cast doubts as to the veracity of Caucasian-Americans' reports of racial egalitarianism. It is reasonable to suppose that most Caucasian-Americans consciously intend to demonstrate egalitarian behavior toward other racial groups. However, implicit biases, often measured using response latency techniques, may lead to prejudicial behavior despite the individual's best conscious intentions.

Recently, progress has been made to demonstrate that individuals who report nonprejudiced attitudes may actually hold negative attitudes outside of their conscious awareness or control. These studies rely on response latency to demonstrate that evaluative preferences exist beneath the level of conscious awareness, at the level of memory. In one recent study, participants judged positive and negative adjectives as either 'good' or 'bad', which had earlier been primed by Black or White faces (Fazio, Jackson, Dunton, \& Williams, 1995). Fazio and colleagues claimed that response latency measured the automatic evaluative preference of the primed faces. They found that White participants categorized 'good' words more quickly when preceded by White faces than when preceded by Black faces. Conversely, White participants categorized 'bad' words more quickly when preceded by Black faces than when preceded by White faces. 
Black participants showed the opposite results - Black faces facilitated categorization of 'good' words and inhibited categorization of 'bad' words. Interestingly, this measure of automatic preference did not correlate strongly with standard explicit measures of attitudes toward African-Americans, suggesting that automatic attitudes may represent a different attitudinal construct.

However, the authors did find a number of interesting relationships between the implicit measure and other outcome variables. One particularly intriguing correlation was found between participants' automatic attitudes and experimenter-judged friendliness of participants, such that participants with more negative automatic attitudes toward Blacks were perceived as less friendly by the Black experimenter blind to knowledge about subjects automatic race evaluations. Additionally, they found a correlation between participants' automatic attitudes and participants' ratings regarding who should be held responsible for the riots following the Rodney King verdict. Specifically, participants with more negative automatic attitudes toward Blacks attributed greater responsibility to the Black community (relative to responsibility attributed to the police). These results, using response latency measurement, effectively captured evaluative preferences that exist outside of conscious control and awareness. Furthermore, this methodology demonstrated that implicit preferences do play a role in guiding behavior.

Similar to Fazio and his colleagues, Dovidio, Kawakami, Johnson, Johnson, and Howard (1997) measured automatic preferences using a response latency procedure that measured the degree of association between racial categories and evaluative preferences. They found that explicit measures of racial attitudes predicted conscious, deliberative race-related responses. However, it was the response latency measures of automatic 
attitudes that predicted spontaneous (non-deliberative) race-related responses. In addition, the automatic attitude measures predicted actual nonverbal behaviors in a mixed race interaction (e.g., amount of eye contact with an individual from a different racial group). ${ }^{7}$

Response latency has been especially important in this area of research because it has led to the revelation that mental representations can represent attitudes which are unrelated to explicitly reported attitudes. It is not clear from these studies whether the desynchronous relationship between explicit and implicit measures is due to real differences in the attitude measures themselves, or to effortful controlling of explicit attitudes due to social desirability pressures. In either case, response latency measurement has added a critical dimension to the investigation of attitudinal judgments and their links to behavior.

Response latency measures have advanced attitude research by outlining both the ways that attitude accessibility can affect consequent behavior, and by demonstrating that attitudes can exist at the level of memory. Evaluation can occur automatically, effortlessly, and unconsciously. The most challenging conclusion from this area of research is that our attitudes toward social objects, and subsequent behavior toward those objects, may not always be directed by our conscious intentions. Implicit biases appear to guide not only our judgments, but also our behavior in a variety of situational contexts. These findings bring to light the prospect that as policy makers move forward to try and address the racial biases still evident in our society, they will need to attend to attitudes

\footnotetext{
${ }^{7}$ A new response latency technique has been developed to measure automatic attitudes (Greenwald, McGhee, \& Schwartz, 1998). This powerful new technique is undergoing rigorous investigation by over 100 researchers worldwide. It is described and demonstrated at a website developed by the author, and mentioned in the postscript.
} 
that exist at both the conscious and the implicit level if they hope to achieve behavioral change.

\section{Conclusion}

The breadth of applications of response latency methodology reviewed in this paper evidences its usefulness as a dependent measure. Social psychological research has benefited from the use of response latency as a measure of underlying mental representation, cognitive process, and motivation. Social psychology has co-opted this technique and applied it broadly and cleverly to investigate issues ranging from close relationships to implicit attitudes.

The large variety of applications and interpretations of response latency methods reviewed in this paper emphasizes the importance of proper experimental design and interpretation. Interpretation of response latency is dependent on (1) the type of

judgment made by respondents, (2) the context in which the response is made, and (3) the design of the conditions being compared (Fazio, 1986). Inattention to the details of experimental design makes sensitive measures like response latency more troublesome and less informative. In general, social psychological research using response latency is designed to manipulate specific, targeted variables where a simple difference in response latency can infer a fundamental difference in cognition.

General applications of response latency to Social psychological research examine (1) how information is processed and stored in memory, (2) how those memories impact on processing of new information, (3) how the mental representations of social objects impact behavior in the presence of those objects, and (4) motivational aspects of human behavior. These categories of interpretation have enabled researchers 
using response latency to make useful contributions to interpersonal dynamics and intrapersonal cognition. Studying mental events as they happen extends psychologist's ability to investigate the structure and process of cognition, and its impact on our social behavior.

\section{Postscript}

To expand my knowledge and use of response latency as a methodological tool, I implemented a website that allows demonstrations of a particular response latency methodology, the Implicit Association Test (Greenwald, McGhee, \& Schwartz, 1998). Development of this website required that I challenge and broaden my methodological and technical knowledge. This effort will ultimately enable large-scale, distant data collection opportunities, as well as encourage greater dissemination of the ongoing research in my laboratory (under the direction of Mahzarin Banaji).

I consider this project to be one of the most important components of my graduate education, and I believe it will have extensive benefits for my research career. I now have the aptitude to work with a medium new to psychology, the Internet, which is likely to change the way research is done. Also, I have a better handle on the methodological and technical developments necessary to make the Internet a viable source for data collection. I intend to continue development of this website to produce a fully functional research site. I consider this project to be as part of my fulfillment of the theme essay requirement. The website can be viewed at http://www.yale.edu/implicit. 


\section{References}

Anderson, J.R. (1987). Skill acquisition: Compilation of weak-method problem solutions. Psychological Review, 94, 192-210.

Aron, A., Aron, E.N., \& Smollan, D. (1992). Inclusion of other in the self scale and the structure of interpersonal closeness. Journal of Personality and Social Psychology, 63, 596-612.

Aron, A., Aron, E.N., Tudor, M., \& Nelson, G. (1991). Close relationships as including the other in the self. Journal of Personality and Social Psychology, $\underline{60}, 241-253$.

Baldwin, M.W., \& Sinclair, L. (1996). Self-esteem and “if...then" contingencies of interpersonal acceptance. Journal of Personality and Social Psychology, $\underline{71}, 1130$ 1141.

Baldwin, M.W., Fehr, B., Keedian, E., Seidel, M., \& Thompson, D.W. (1993). An exploration of the relational schemata underlying attachment styles: Self report and lexical decision approaches. Personality and Social Psychology Bulletin, 19 , 746-754.

Banaji, M.R., \& Hardin, C. (1996). Automatic stereotyping. Psychological Science, $\underline{7}, 136-141$.

Bargh, J.A., Chen, M., \& Burrows, L. (1996). Automaticity of social behavior: Direct effects of trait construct and stereotype activation on action. Journal of Personality and Social Psychology, 71, 230-244.

Bassili, J.N. (1995). Response latency and the accessibility of voting intentions: What contributes to accessibility and how it affects vote choice. Personality and Social Psychology Bulletin, 21, 686-695. 
Bassili, J.N., \& Racine, J.P. (1990). On the process relationship between person and situation judgments in attribution. Journal of Personality and Social Psychology, 59, 881-890.

Blair, I.V., \& Banaji, M.R. (1996). Automatic and controlled processes in stereotype priming. Journal of Personality and Social Psychology, $\underline{70}, 1142-1163$.

Bless, H., \& Fiedler, K. (1995). Affective states and the influence of activated general knowledge. Personality and Social Psychology Bulletin, 21, 766-778.

Boer, L.C. (1995). Taskomat: Evaluation of a computerized test battery. International Journal of Selection and Assessment, $\underline{3}, 105-113$.

Burtt, H.E. (1941). The association reaction as a measurement of attitude.

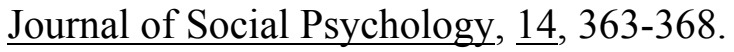

Campbell, J.D., \& Fairey, P.J. (1989). Informational and normative routes to conformity: The effect of faction size as a function of norm extremity and attention to the stimulus. Journal of Personality and Social Psychology, 57, 457-468.

Carlston, D.E., \& Skowronski, J.J. (1986). Trait memory and behavior memory: The effects of alternative pathways on impression judgment response times, 50, 5-13.

Cartwright, D. (1941). Relation of decision-time to the categories of response. American Journal of Psychology, 54, 174-196.

Cervin, V. (1955). Experimental investigation of behavior in social situations: II. Individual behavioral effects of change in group attitude from opposition to cooperation. Canadian Journal of Psychology, 9, 155-160. 
Deutsch, M., \& Gerard, H.B. (1955). A study of normative and informational social influence upon individual judgment. Journal of Abnormal and Social Psychology, 51, 629-636.

Dijksterhuis, A. et al. (1998). Seeing one thing and doing another: Contrast effects in automatic behavior. Journal of Personality and Social Psychology, 75, 862-871.

Dovidio, J.F., Evans, N., \& Tyler, R.B. (1986). Racial stereotypes: The contents of their cognitive representations. Journal of Experimental Social Psychology, 22, 22-37.

Dovidio, J.F., Kawakami, K., Johnson, C., Johnson, B., \& Howard, A. (1997). On the nature of prejudice: Automatic and controlled processes. Journal of Experimental Social Psychology, 33, 510-540.

Eagly, A.H. \& Chaiken, S. (1998). Attitude structure and function. Gilbert, D.T., Fiske, S.T., \& Lindzey, G. (Eds.) The Handbook of Social Psychology Vol. I. (pp. 269322) New York, NY: McGraw-Hill.

Ellsworth, P.C., Carlsmith, J.M., \& Henson, A. (1972). The stare as a stimulus to flight in human subjects. Journal of Personality and Social Psychology, 21, 302-311.

English, H.B. (1926). Reaction-time symptoms of deception. American Journal of Psychology, 37, 428-429.

Fazio, R.H. (1989). On the power and functionality of attitudes: The role of attitude accessibility. In A.R. Pratkanis, S.J. Breckler, \& A.G. Greenwald (Eds.), Attitude

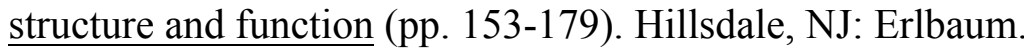

Fazio, R.H. (1990). A practical guide to the use of response latency in social psychological research. In C. Hendrick \& M.S. Clark (Eds.), Research methods in Personality and Social Psychology, (Vol. 11, pp. 74-97). Newbury Park: Sage. 
Fazio, R.H., \& Williams, C.J. (1986). Attitude accessibility as a moderator of the attitude-perception and attitude-behavior relations: An investigation of the 1984 presidential election. Journal of Personality and Social Psychology, 51, 505-514.

Fazio, R.H., Blascovich, J., \& Driscoll, D.M. (1992). On the functional value of attitudes: The influence of accessible attitudes on the ease and quality of decision making. Personality and Social Psychology Bulletin, 18, 388-401.

Fazio, R.H., Chen, J., McDonel, E.C., \& Sherman, S.J. (1982). Attitude accessibility, attitude-behavior consistency, and the strength of the object-evaluation association. Journal of Experimental Social Psychology, 18, 339-357.

Fazio, R.H., Jackson, J.R., Dunton, B.C., \& Williams, C.J. (1995). Variability in automatic activation as an unobtrusive measure of racial attitudes: A bona fide pipeline? Journal of Personality and Social Psychology, 69, 1013-1027.

Ferguson, T.J., \& Wells, G.L. (1980). Priming of mediators in causal attribution.

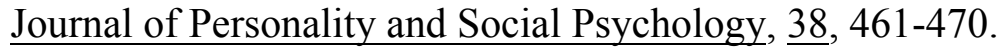

Fiske, S.T. (1998). Stereotyping, prejudice, and discrimination. Gilbert, D.T., Fiske, S.T., \& Lindzey, G. (Eds.) The Handbook of Social Psychology Vol. II. (pp. 357414) New York, NY: McGraw-Hill.

Forgas, J.P. (1992). On mood and peculiar people: Affect and person typicality in impression formation. Journal of Personality and Social Psychology, 63, 863-875.

Forgas, J.P. (1993). On making sense of odd couples: Mood effects on the perception of mismatched relationships. Personality and Social Psychology Bulletin, 19, 59-70. 
Forgas, J.P. (1994). Sad and guilty? Affective influences on the explanation of conflict in close relationships. Journal of Personality and Social Psychology, $\underline{66}, 56-68$.

Forgas, J.P., \& Fiedler, K. (1996). Us and them: Mood effects on intergroup discrimination. Journal of Personality and Social Psychology, 70, 28-40.

Gilbert, D.T., \& Krull, D.S. (1988). Seeing less and knowing more: the benefits of perceptual ignorance. Journal of Personality and Social Psychology, 54, 193-202.

Gilbert, D.T., Fiske, S.T., \& Lindzey, G. (Eds.) (1998). The Handbook of Social Psychology. New York, NY: McGraw-Hill.

Gilbert, D.T., Krull, D.S., \& Pelham, B.W. (1988). Of thoughts unspoken: Social inference and the self-regulation of behavior. Journal of Personality and Social Psychology, 55, 685-694.

Glanzer, M., \& Nolan, S.D. (1986). Memory mechanisms in text comprehension. In G.H. Bower (Ed.), The psychology of learning and motivation (vol 20, pp. 275-317). Orlando, Fl: Academic Press.

Greenbaum, P., \& Rosenfeld, H.M. (1978). Patterns of avoidance in response to interpersonal staring and proximity: Effects of bystanders on drivers at a traffic intersection. Journal of Personality and Social Psychology, 36, 575-587.

Greenwald, A.G., \& Banaji, M.R. (1995). Implicit social cognition: Attitudes, self-esteem, and stereotypes. Psychological Review, 102, 4-27.

Greenwald, A.G., Klinger, M.R., \& Lui, T.J. (1989). Unconscious processing of dichoptically masked words. Memory and Cognition, 17, 35-47. 
Greenwald, A. G., McGhee, D. E., \& Schwartz, J. L. K. (1998). Measuring individual differences in implicit cognition: The implicit association test. Journal of Personality and Social Psychology, 74, 1464-1480.

Hamilton, D. (1988). Causal attribution viewed from an informaiton processing perspective. In D. Bar-Tel \& A.W. Kruglanski (Eds.), The social psychology of knowledge (pp. 359-385). Cambridge, England: Cambridge University Press.

Heider, F. (1958). The psychology of interpersonal relations. New York: Wiley. Hoeksema-van Orden, C.Y.D., Gaillard, A.W.K., \& Buunk, B.P. (1998). Social loafing under fatigue. Journal of Personality and Social Psychology, 75, 1179-1190.

Kardes, F.R., Sanbonmatsu, D.M., Voss, R.T., \& Fazio, R.H. (1986). Selfmonitoring and attitude accessibility. Personality and Social Psychology Bulletin, $\underline{12}$, 468-474.

Kelley, H.H. (1967). Attribution theory in social psychology. In D. Levine (Ed.), Nebraska Symposium on Motivation (Vol. 15). Lincoln: University of Nebraska Press.

Knox, R.E., \& Douglas, R.L. (1971). Trivial incentives, marginal comprehension, and dubious generalizations from prisoner's dilemma studies. Social Psychology, 20, 160-165.

Krosnick, J.A. (1989). Attitude importance and attitude accessibility. Personality and Social Psychology Bulletin, 15, 297-308.

Markus, H. (1977). Self-schemata and processing information about the self. Journal of Personality and Social Psychology, 35, 63-78. 
Marston, W.M. (1920). Reaction-time symptoms of deception. Journal of Experimental Psychology, ??, 80-82.

Marston, W.M. (1925). Negative type reaction-time symptoms of deception. Psychological Review, 32, 241-247.

Mellema, A., \& Bassili, J.N. (1995). On the relationship between attitudes and values: Exploring the moderating effects of self-monitoring and self-monitoring schematicity. Personality and Social Psychology Bulletin, 21, 885-892.

Mikulincer, M. (1998). Attachment working models and the sense of trust: An exploration of interaction goals and affect regulation. Journal of Personality and Social Psychology, 74, 1209-1224.

Mills, C.J. (1983). Sex-typing and self-schemata effects on memory and response latency. Journal of Personality and Social Psychology, 45, 163-172.

Moskowitz, G.B., \& Roman, R.J. (1992). Spontaneous trait inferences as selfgenerated primes: Implications for conscious social judgment. Journal of Personality and Social Psychology, 62, 728-738.

Mueller, J.H., Thompson, W.B., \& Dugan, K. (1986). Trait distinctiveness and accessibility in the self-schema. Personality and Social Psychology Bulletin, 12 , 81-89.

Mueller, Ross, \& Heesacker, (1984). Distinguishing me from thee. Bulletin of the Psychonomic Society, 22, 79-82.

Neidenthal, P.M. (1990). Implicit perception of affective information. Journal of Experimental Social Psychology, 26, 505-527.

Osgood, C.E. (1941). Ease of individual judgment-process in relation to polarization of attitudes in the culture. Journal of Social Psychology, 14, 403-418. 
Park, B. (1986). A method for studying the development of impressions of real people. Journal of Personality and Social Psychology, 51, 907-917.

Paulhus, D.L., \& Levitt, K. (1987). Desirable responding triggered by affect: Automatic egotism? Journal of Personality and Social Psychology, 52, 245-259.

Posner, M.I. (1978). Chronometric explorations of the mind. New York, NY: Lawrence Erlbaum.

Powell, M.C., \& Fazio, R.H. (1984). Attitude accessibility as a function of repeated attitudinal expression. Personality and Social Psychology Bulletin, $\underline{10}, 139-148$.

Roese, N.J., \& Olson, J.M. (1994). Attitude importance as a function of repeated attitude expression. Journal of Experimental Social Psychology, 30, 39-51.

Ross, Mueller, \& de la Torre, (1986). Depression and trait distinctiveness in the self-schema. Journal of Social and Clinical Psychology, 4, 46-59.

Smith, E.R., \& Henry, S. (1996). An in-group becomes part of the self: Response time evidence. Personality and Social Psychology Bulletin, 22, 635-642.

Smith, E.R., \& Miller, F.D. (1979). Attributional information processing: A response time model of causal attribution. Journal of Personality and Social Psychology, $\underline{37}, 1723-1731$.

Srull, T.K. (1984). Methodological techniques for the study of person memory and social cognition. In R. Wyer \& T.K. Srull (Eds.), Handbook of Social Cognition. Hillsdale, NJ: Lawrence Erlbaum.

Srull, T.K., \& Wyer, R.S. Jr. (1989). Person memory and judgment. Psychological Review, 96, 58-83. 
Srull, T.K., \& Wyer, R.S., Jr. (1979). The role of category accessibility in the interpretation of information about persons: Some determinants and implications. Journal of Personality and Social Psychology, 37, 1660-1672.

Stewart, T.L., Doan, K.A., Gingrich, B.E., \& Smith, E.R. (1998). The actor as context for social judgments: Effects of prior impressions and stereotypes. Journal of Personality and Social Psychology, 75, 1132-1154.

Stroessner, S.J. (1996). Social categorization by race or sex: Effects of perceived non-normalcy on response times. Social Cognition, $\underline{14}$, 247-276.

Thompson, E.P., Roman, R.J., Moskowitz, G.B., Chaiken, S., \& Bargh, J.A. (1994). Accuracy motivation attenuates covert priming: The systematic reprocessing of social information. Journal of Personality and Social Psychology, $\underline{66}, 474-489$.

Thomsen, C.J., Lavine, H., \& Kounios, J. (1996). Social value and attitude concepts in semantic memory: Relational structure, concept strength, and the fan effect.

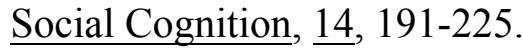

Tourangeau, R., Rasinski, K.A., \& D’Andrade, R. (1991). Attitude structure and belief accessibility. Journal of Experimental Social Psychology, 27, 48-75.

Trope, Y. (1989). The multiple role of context in dispositional judgment. In J.N. Bassili (Ed.), On-line cognition in person perception (pp. 123-140). Hillsdale, NJ: Erlbaum.

Turner, R.G. (1978). Self-consciousness and speed of processing self-relevant information. Personality and Social Psychology Bulletin, 4, 456-460.

Uleman, J.S., \& Bargh, J.A. (Eds.), (1989). Unintended Thought. New York: Guilford. 
von Neumann and Flood (1952).

Whitney, P., Davis, P.A., \& Waring, D.A. (1994). Task effects on trait inference: Distinguishing categorization from characterization. Social Cognition, 12, 19-35.

Zajonc, R.B. (1998). Emotions. Gilbert, D.T., Fiske, S.T., \& Lindzey, G. (Eds.) The Handbook of Social Psychology Vol. I. (pp. 591-634) New York, NY: McGrawHill.

Zarate, M.A., \& Smith, E.R. (1990). Person categorization and stereotyping. $\underline{\text { Social Cognition, }} \underline{8}, 161-185$.

Zuckerman, M., \& Evans, S. (1984). Schematic approach to the attributional processing of actions and occurrences. Journal of Personality and Social Psychology, 47, $469-478$. 